\title{
Serra Acima: (re)significação territorial de comunidades quilombolas de Chapada dos Guimarães (MT)
}

\author{
Cassiana Oliveira da Silva ${ }^{1}$ \\ Marina Mantovani Rodrigues de Castro ${ }^{2}$ \\ José Batista Franco Junior 3 \\ Universidade Federal de Mato Grosso
}

Resumo: A partir das experiências etnográficas em três comunidades quilombolas localizadas no município de Chapada dos Guimarães, Mato Grosso, o texto aborda as conexões e as inter-relações que constituem as pessoas quilombolas de Lagoinha de Cima, Ribeirão Itambé e Morro do Cambambi. A importância de suas histórias e ancestralidades ligadas aos seus territórios existenciais delineiam significados através das relações estabelecidas por esses grupos com o território na construção de uma territorialidade específica que expande os limites do território tradicionalmente ocupado e se expressa na luta por direitos. Assim, o universo simbólico analisado nos permite pensar a territorialidade como alicerce nos processos de sociabilidades e na construção dessas pessoas e identidades quilombolas. Ao apresentar brevemente as três etnografias, este artigo propõe refletir sobre as formas de tecer relações, trocas, espaços e como essas pessoas quilombolas (re)significam seu território onde quer que estejam.

Palavras-chaves: território; quilombolas; política; Chapada dos Guimarães.

${ }^{1}$ Mestranda em Antropologia Social do Programa de Pós-Graduação em Antropologia Social da Universidade Federal de Mato Grosso (PPGAS/UFMT). Licenciada em Ciências Sociais pela Universidade Federal de Mato Grosso (UFMT).

${ }_{2}$ Mestre em Antropologia Social junto ao Programa de Pós-Graduação em Antropologia Social da Universidade Federal de Mato Grosso (PPGAS/UFMT). Licenciada em Ciências Biológicas pela UFMT e pela Universidade do Porto (Portugal). 3 Mestre em Antropologia Social pelo Programa de Pós-Graduação em Antropologia Social da Universidade Federal de Mato Grosso (PPGAS/UFMT). Bacharel em Direito pela Universidade do Estado de Mato Grosso (Unemat). 


\title{
Serra Acima: \\ territorial (re)meaning of quilombolas communities in Chapada dos Guimarães (MT)
}

\begin{abstract}
Based on ethnographic experiences in three quilombola communities located in the municipality of Chapada dos Guimarães, Mato Grosso, this article addresses the connections and inter-relationships that constitute quilombola people of Lagoinha de Cima, Ribeirão Itambé and Morro do Cambambi. The importance of their histories and ancestry linked to their existential territories delineate meanings through the relations established by these groups with the territory in the construction of a specific territoriality that expands the limits of the territory traditionally occupied and that is expressed in their fight for rights. Thus, the symbolic universe analyzed allows us to think of territoriality as a basis in the processes of sociability and construction of these quilombola people and identities. In briefly presenting the three ethnographies, this article proposes to reflect on the ways of weaving relationships, exchanges, spaces and how these quilombola people (re)mean their territory wherever they are.
\end{abstract}

Keywords: territory; quilombolas; policy; Chapada dos Guimarães.

\section{Serra Acima: Re-significación territorial de comunidades quilombolas de Chapada dos Guimarães (MT)}

\begin{abstract}
Resumen: A partir de las experiencias etnográficas en tres comunidades quilombolas ubicadas en el municipio de Chapada dos Guimarães, Mato Grosso, el texto aborda las conexiones e interrelaciones que constituyen el pueblo quilombola de Lagoinha de Cima, Ribeirão Itambé y Morro do Cambambi. La importancia de sus historias y ascendencia conectada a sus territorios existenciales delinean significados a través de las relaciones que estos grupos establecen con el territorio en la construcción de una territorialidad específica que amplía los límites del territorio tradicionalmente ocupado y se expresa en la lucha por los derechos. Así, el universo simbólico analizado permite pensar en la territorialidad como fundamento en los procesos de sociabilidad y en la construcción de estos pueblos e identidades quilombolas. Al presentar brevemente las tres etnografías, este artículo propone reflexionar sobre las formas de tejer relaciones, intercambios, espacios y cómo estos quilombolas (re) entienden su territorio dondequiera que estén.
\end{abstract}

Palabras claves: territorio; quilombolas; política; Chapada dos Guimarães. 


\section{De Serra Acima à Chapada dos Guimarães}

$\mathrm{D}$ iversos estudos históricos e antropológicos têm comprovado a presença de populações humanas no território de Chapada dos Guimarães desde muitos séculos atrás, com sítios onde é possível perceber, em cavernas, cachoeiras e paredões, inúmeros registros de populações que habitaram essa região de chapada no cerrado mato-grossense. Apesar dos vestígios de que o território de Mato Grosso tenha entrado para a História Nacional a partir de 1719, Madureira (2006) elucida que na região já havia a presença de espanhóis e portugueses que por ali já trafegavam, incluindo registros sobre a passagem de bandeirantes pela região anteriormente a esse período.

Contudo, o território de Chapada dos Guimarães, antes da colonização, era de ocupação indígena. Povos das etnias Bóe (Bororo) 4 e Kurâ (Bakairi) 5 reconhecem a região desse território como terra ancestral. O processo de colonização teve como marco a subida de parte da população de Cuiabá para Chapada dos Guimarães, onde passaram a cultivar milho, mandioca, feijão, cana de açúcar e até mesmo café, se beneficiando da temperatura mais baixa em relação à Cuiabá. $\mathrm{O}$ povoamento de Chapada deve sua origem na construção da aldeia indígena na missão Jesuíta de Santana do Sacramento, também chamada de Sant'Anna de Chapada, fazendo referência a um lugar conhecido como "Aldeia Velha", do denominado distrito de Serra Acima (SILVA, 2017: 29).

O primeiro colono a se instalar em Serra Acima foi Antônio de Almeida Lara que ali desenvolveu agricultura de subsistência, montou engenhos de farinha e de cana, abastecendo as minas de Cuiabá por quase todo o período colonial (MADUREIRA, 2006: 47). Os primeiros registros oficiais de escravos na região coincidem com a sua invasão pelos bandeirantes paulistas e uma ocupação faz referência à carta de doação da "Sesmaria do Capitão General da Capitania de São Paulo, Rodrigo Cezar de Menezes, ao então Tenente Coronel Antônio de Almeida Lara”, paulista que justifica a doação por estar "afazendado na Chapada", distante aproximadamente 10 léguas das minas de ouro de Cuiabá, com plantações de cana, criações de gado, roça, onde trabalhavam mais de 30 escravos (CRIVELENTE, 2003: 131).

Madureira (2006) afirma que o povoamento de Chapada não teria sido somente para instalação de grandes propriedades agrícolas, mas também para o incremento da mineração, principal atividade da região na época, devido a quantidade de rios que favoreciam a extração de minérios, especialmente no rio Quilombo, onde em quase toda a sua extensão proliferaram pequenas jazidas diamantíferas.

Os senhores de engenho de Serra Acima, como era conhecida a região, eram oficiais militares (alferes, sargentos, tenentes, capitães), e que usufruíam de privilégios concedidos devido ao seu status social. A região militarizada atendia aos interesses da Corte ao ter seus oficiais em terras limítrofes com as províncias da Espanha, dando-lhe segurança na defesa de suas invadidas em 1719.

\footnotetext{
${ }^{4}$ Os Bororo se autodenominam Boe. Pertencem à família linguística bororo e ocupam atualmente seis Terras Indígenas no Estado de Mato Grosso: Meruri, Perigara, Sangradouro/Volta Grande, Tadarimana, Jarudori e Teresa Cristina. Disponível em:< https://pib.socioambiental.org/pt/Povo:Bororo >. Acessado em: 15 de janeiro de 2020.

${ }^{5}$ Os Bakairi se autodenominam Kurâ, que quer dizer "gente", "pessoa", "ser humano". Pertencem a família linguística Karib e vivem no estado de Mato Grosso, nas Terras Indígenas Bakairi (município de Paranatinga e Planalto da Serra) e Santana (município de Nobres). Disponível em: < https://pib.socioambiental.org/pt/Povo:Bakairi >. Acessado em: 15 de janeiro 2020.
} 
Florence (1977) conta que, durante sua viagem à Chapada, visitou a região do rio Quilombo e descreveu:

\begin{abstract}
O terreno está cheio de seixos grandes e miúdos: é a matriz ordinária ou canga em que se encontram os diamantes. Estivemos uma hora parados perto de mineiros ocupados em catar a preciosa gema. Veem-se muitas canoas ao longo de um filete d'água. Dá-se o nome de canoa a um paralelogramo de cinco pés de comprido sobre três de largo, de terra batida, e junto a um córrego, riacho ou a uma lagoa: tem a superfície em declive e os lados, em exceção do que é formado pela água, fechados por toros de pau deitados, que servem de encaixe. O trabalhador cava grandes buracos quadrados e aos poucos transporta para a canoa o cascalho, sobre o qual atira um bocado de água para que esta ao escorrer carregue a terra solta para o córrego e deixe o monte mais limpo. Então, coloca uma pequena porção desses seixinhos na beira da bateia (alguidar redondo de pau e fundo cônico, com 18 a 20 polegadas de diâmetro sobre três de altura) e começa a agitar circularmente a água, de modo que esta, lambendo o cascalho, leva a menor porção possível, a fim de depositar no fundo e deixar ver os diamantes, se houver, por pequenos que sejam. (FLORENCE, 1977: 69-70)
\end{abstract}

A grande presença de negros na região refletia tal momento de sucesso da economia regional com a extração de grande quantidade de ouro. Symanski (2010), por meio de uma incidência de vestígios arqueológicos, demonstra a pluralidade da presença negra africana em Chapada dos Guimarães, evidente nas pinturas, desenhos identitários e nas cerâmicas desenvolvidas por eles.

Dados do século XVIII, a respeito dos engenhos de aguardente e monjolos de farinha em Mato Grosso, indicam que Serra Acima (Chapada) apresentava cerca de vinte e dois engenhos e seis monjolos. Dos diversos distritos da província de Mato Grosso, Serra Acima era o que mais possuía escravos, tendo setecentos e trinta e oito ao certo, crescimento esse oriundo da expansão agrícola na produção de aguardente e no fornecimento de itens de subsistência, como: milho, café, mandioca, feijão, produtos de origem indígena, tendo o seu auge entre as décadas de 1820-1830 e 1850-1865 (CRIVELENTE, 2003: 134).

A região do rio Quilombo foi palco de inúmeros conflitos durante o século XIX, entre militares e quilombolas, uma vez que em suas imediações, como no rio da Casca e do Manso, foi onde proliferaram os quilombos. Ali estavam assentadas grandes propriedades, em sua maioria engenhos, que utilizavam grande quantidade de mão-de-obra escrava. Destaca-se a sesmaria de Antônio Dias Lessa, que mantinha engenhos de cana-de-açúcar e farinha; a sesmaria de Inácio de Borba Gato, cujo o engenho ganhou o nome de Itambé; e a grande e propalada sesmaria de Antônio Bruno Borges, proprietário da sesmaria Mamão, que mantinha engenhos de cana, aparelhagem de ferro e grande número de escravos. Antônio Bruno Borges foi um dos senhores de engenhos que financiou várias expedições contra quilombos, no objetivo de recapturar seus escravos fugidos (MADUREIRA, 2006: 73).

Os estudos antropológicos sobre os quilombos de Chapada dos Guimarães são poucos e recentes (SILVA, 2014; LOURENÇO, 2015; LOURENÇO, 2016; SILVA, 2017; CASTRO, 2018; RODRIGUES, 2018; OLIVEIRA, 2018; VITHOFT, 2018; FRANCO JUNIOR, 2020). A discussão e pesquisa em tela busca retratar o recorte de três trabalhos de cunho etnográfico sobre as comunidades quilombolas - CRQ Ribeirão Itambé, CRQ Morro do Cambambi e CRQ Lagoinha de Cima, fruto de etnografias realizadas em momentos distintos, etnografias e pesquisas coletivas e individuais.

A etnografia da Comunidade Quilombola Lagoinha de Cima foi realizada durante a escrita da dissertação de mestrado de Marina Mantovani Rodrigues de Castro6 $^{6}$, de 2016 a 2018. A etnografia da Comunidade Quilombola Ribeirão 
Itambé foi realizada durante pesquisa para o Trabalho de Conclusão de Curso ${ }^{7}$, de 2015 a 2017, e atual escrita da dissertação da mestranda Cassiana Oliveira da Silva. A etnografia do Morro do Cambambi foi realizada entre 2017 e 2019 por José Batista Franco Junior8. Importante se faz pontuar que, por muitas vezes, compartilhamos idas ao campo, reflexões e caminhos durante a escrita de nossos trabalhos individuais, mas que possuem significativas contribuições coletivas ${ }^{9}$ também.

A partir do breve contexto do território de Chapada dos Guimarães, objetivase versar sobre como esses sujeitos, nesse processo histórico, ressignificam seus territórios e geometrizam formas de habitar, que constituem, a um só tempo, um agenciamento político e um ampliador das ideias pré-concebidas sobre as comunidades quilombolas.

O estudo de O’Dwyer ressalta que,

\begin{abstract}
O termo "quilombo" não se refere a resíduos ou resquícios arqueológicos de ocupação temporal ou de comprovação biológica. Também não se trata de grupos isolados ou de uma população estritamente homogênea. Nem sempre foram constituídos a partir de movimentos insurrecionais ou rebelados, mas, sobretudo, consistem em grupos que desenvolveram práticas cotidianas de resistência na manutenção e reprodução de seus modos de vida característicos e na consolidação de um território próprio. (O’DWYER, 2002: 18)
\end{abstract}

Apesar das pesquisas de campo terem sido realizadas em fases distintas por cada pesquisador, ela aponta que os territórios desses quilombos, que estão em uma relação de contiguidade territorial, estão permeados pela existência de uma rede de parentesco e outras relações sociais e territoriais que assinalam para a existência de uma identidade política e de constituição das próprias pessoas, fundada em uma "territorialidade negra" (BANDEIRA, 1991).

Conforme o dispositivo da Constituição Federal Brasileira de 1988, o artigo 68 dos Atos das Disposições Constitucionais Transitórias (ADCT), prevê "aos remanescentes das comunidades quilombolas que estejam ocupando suas terras o reconhecimento da propriedade definitiva, devendo o Estado lhes emitirem os títulos respectivos". Cabe ressaltar que a luta pela terra antecede o reconhecimento jurídico como "remanescentes de quilombos".

Logo, ressignificando suas formas de habitar, os quilombolas de Chapada dos Guimarães agenciam uma rede de relações que se constituem em ação política. Para eles, morar é um ato político. Resistir por meio dos laços de parentescos (mesmo que fora do território tradicional) é uma ação política. Desta forma, apresentamos a seguir três recortes etnográficos, das comunidades quilombolas Lagoinha de Cima, Ribeirão Itambé e Morro do Cambambi, cuja configuração territorial, embora distinta, aponta para uma extensa "rede de sociabilidade" de uso comum e coletivo da terra, versando sobre como esses sujeitos territorializam seus espaços, constituindo múltiplas formas de habitar, ser e (re)existir.

\title{
I. Comunidade Quilombola de Lagoinha de Cima
}

Lagoinha de Cima é uma comunidade quilombola localizada nas extremidades rurais e ruralistas da cidade mato-grossense de Chapada dos Guimarães, cerca de 30 quilômetros do centro da cidade, nas margens do rio Lagoinha. Rio 
este que também nomeia a comunidade vizinha e contígua territorialmente, Lagoinha de Baixo, que compartilha ancestralidade, histórias e parentesco com as pessoas de Lagoinha de Cima desde o período colonial (LOURENÇO, 2015).

O engenho do Abrilongo marca o limite territorial entre as duas comunidades e faz parte das memórias e da vida das pessoas de ambas as comunidades, principalmente das pessoas mais velhas, que se recordam dos momentos de violência vividos no local e das histórias que os parentes contavam. Em Lagoinha de Cima, Dona Vanildes, uma das pessoas mais antigas da comunidade, sempre citava Salomé, mãe de Lorinda, sua antiga vizinha, quando perguntado sobre o engenho.

\begin{abstract}
Aqui tinha escrava sim, a vó do Nego, aquele que tava aqui agora mesmo, que era a Lorinda, que morava aqui no fundo, falava que a mãe dela viveu no tempo dos escravos. Trabalhava e eles não pagavam nada para ela não, era de graça, e ainda batiam, faziam ela cavar a própria cova. Tudo isso lá na Bilonga [Abrilongo] ali, eu mesmo vi as covas, tinha tudo lá, agora não tem mais nada lá não. ${ }^{10}$
\end{abstract}

Dona Vanildes também conta que "essa época dos escravos acabou" quando uma senhorinha libertou as pessoas e começou a pagar pelos trabalhos realizados no engenho, nas plantações e cercas. Neste processo, a população da comunidade construiu e consolidou sua moradia nos arredores do Abrilongo, na parte de cima e de baixo das margens do rio Lagoinha.

Além da história marcada pela escravidão, as pessoas da comunidade vivenciaram (e ainda vivem), constantes conflitos e violências decorrentes da invasão de seu território. Atualmente, cerca de 14 famílias que vivem no território tradicional, cercadas por grandes monoculturas de soja, milho e algodão, que despejam grandes quantidades diárias de agrotóxicos, contaminando o ar, a água, o solo e as plantações, prejudicando a saúde e a vida dos moradores.

A perda de grande parte do território, o medo de novas invasões, a falta de trabalho, educação e saúde na comunidade, fez com que a maioria dos moradores vendessem ou deixassem suas terras para viver nos centros urbanos próximos, nas cidades de Campo Verde, Cuiabá, Várzea Grande e Nova Brasilândia. Mesmo com a distância, a maioria das pessoas mantém os laços e as memórias de suas terras e dos tempos que desfrutavam do uso comum da terra. Essas pessoas continuam a estabelecer trocas, redes de sociabilidade e vínculos de pertencimento com seus territórios de origem. Um dos elos que unem as pessoas da comunidade entre si e com o território são as redes de trocas de alimentos.

$\mathrm{Na}$ maioria dos finais de semana as casas ficam cheias. Se é época de colheita de milho, o ralo é tirado da prateleira para trabalhar no esmiuçar da espiga para o preparo das pamonhas "de doce" e "de sal". Se é mês de aniversário a mesa é coberta com um pano colorido e se enche de refrigerantes, bolo, maionese, arroz e carne assada preparada na churrasqueira cavada no chão (quando a quantidade de visitantes é maior) ou no tonel cortado ao meio, no embalo de caixas de som luminosas e grandes tocando lambadão ou rasqueado ${ }^{11}$. Sempre há motivos para almoços e jantares nas casas dos "mais velhos", nem que seja só para reunir os parentes que moram longe, ver "a vó e o vô" ou retribuir alguma ajuda ofertada anteriormente. Nessas reuniões não se juntam apenas parentes, mas também amigos próximos, vizinhos das fazendas ao redor, eu seja, pessoas a quem se tem algum laço de consideração.

A comida é, para eles, um importante item de trocas e circulação, demonstração de afeto e cuidado, e das qualidades de uma pessoa enquanto "pessoa boa"

10 Entrevista concedida pela Dona Vanildes Francisca de Oliveira, pertencente a comunidade quilombola Lagoinha de Cima, em 17 de março de 2017.

${ }^{11}$ Ritmos tradicionais no Mato Grosso. 
ou "pessoa ruim" na medida em que oferece, dá ou retribui o alimento que se tem. Os alimentos são oferecidos e trocados não apenas em ocasiões de festas e comemorações, mas em desesperadores momentos de pouca colheita, falta de dinheiro, brigas familiares ou perdas de território. Oferece-se um saco de arroz, "ramas" de mandioca, galinha, banha de porco, café e açúcar, alimentos mais comuns nas casas das pessoas da comunidade e produzidos no próprio território.

Certa vez, em uma das visitas à comunidade, Dona Vanildes contou que há anos havia dado "de comer" a um homem da comunidade que estava "passando um apuro" e que batera em sua porta implorando ajuda. Disse que deu o que tinha porque, na época, "as coisas eram mais dificeis" apesar de serem melhores, completou ela. Tempos depois foi ela quem pediu favor ao homem, um real para poder ir ao centro de Chapada dos Guimarães, mas deixou avisado que iria até o banco na cidade e já devolveria o valor emprestado. $\mathrm{O}$ homem se negou a dar, $\mathrm{o}$ que a deixou chateada e fez com que não mantivesse mais contato com ele.

A troca de alimentos pode ser pensada a partir da lógica de reciprocidade da dádiva descrita por Mauss (2003 [1935]) funcionando a partir do movimento de dar, receber e retribuir. No caso da história de Dona Vanildes o elo da reciprocidade na retribuição das diversas ajudas dela para com o homem, no momento em que ela precisava, foi quebrado. Ela esperava que ele tivesse "consideração" por tudo feito por ela nos momentos de dificuldade. A retribuição é praticamente obrigatória, na medida em que não é falada, mas é esperada e cobrada para que se mantenha o ciclo de trocas, que demonstra o reconhecimento e que pode ir, inclusive, além da troca de alimentos, mas também de abrigo e roupas, por exemplo.

Quando a dádiva é quebrada aparecem conflitos que vão além da não retribuição.

[...] o conflito parece estar associado à ausência da dádiva, percebida pelas partes como um insulto. Isto é, a falta de reconhecimento ou os atos de desconsideração, característicos da percepção do insulto nos dois casos, poderiam ser apreendidos como situações nas quais a ausência da dádiva é percebida como a sua negação, [...] consequentemente, como a negação do status ou a rejeição da identidade do interlocutor. (CARDOSO DE OLIVEIRA, 2004)

A "consideração", nesse caso, e como também descreve Pina-Cabral no caso do Baixo Sul da Bahia, é algo que precisa ser manifestado, é tornar público, demonstrar a quem e o quanto se considera.

[...] a consideração é o primeiro passo para o coletivo. [...] A dinâmica da consideração opera, portanto, em todos os níveis de constituição social da pessoa, manifestando-se diferentemente em casa nível como um fator de atualização das relações, produzindo uma afirmação da pessoa na relação. (PINA-CABRAL, 2013: 28)

Trago esses breves relatos para nos colocar a pensar sobre as relações que são estabelecidas entre as pessoas no coletivo, como também no processo de cada uma, não de forma dicotômica e separada, mas conjunta, mútua. A relação de mutualidade (SAHLINS, 2011) nesses processos de trocas cotidianas agrega sentido e significado a vida e as pessoas e mantém a relação e sentimento de pertencimento, mesmo com os parentes e pessoas da comunidade que não vivem mais ali. A produção oriunda dos cultivos no território tradicional continua, assim, a fornecer meios de subsistência, trocas e sociabilidade com os parentes aonde quer que eles estejam, mesmo com as dificuldades que vêm sendo enfrentadas por eles para essa produção.

Esses vínculos são estabelecidos há anos nas visitas para tomar um café durante a tarde, as ofertas de plantas no caso de vizinhos enfermos, ou mesmo 
para levar um doce ou bolo feito no dia. Acabam por ser mantidos nas visitas de finais de semana, ou mesmo nas próprias cidades onde as pessoas passam a viver. Quando várias pessoas mudam para a mesma cidade, o que é bem comum, elas costumam morar em bairros próximos, no mesmo bairro e até em casas lado a lado. É nessa extensão do território existencial, na ressignificação das práticas diárias em diferentes locais, que podemos pensar em como a sociabilidade e as relações com o território, os parentes ou as pessoas que se tem consideração são levados para os espaços em que essas pessoas vivem.

O constituir-se enquanto pessoa envolve uma relação coletiva, "expressa nas ações partilhadas e nas interações pessoais diárias" (OVERING, 1999). Assim, partindo de contribuições de Seeger et al (1979) e Sahlins (2011),

é necessária uma análise mais aprofundada a respeito da constituição das pessoas, partindo do conceito de "mutuality of being", ou seja, mutualidade de ser/estar, entendendo que os laços de interdependência e coexistência partilhados por eles é o que permite a existência da cosmologia e do "ser" quilombola da comunidade de Lagoinha de Cima. (CASTRO, 2018: 54)

Esses laços de interdependência e coexistência partilhados entre as pessoas de Lagoinha de Cima tem apenas um de seus "nós" nas trocas e circulação de alimentos, mas que podem nos demonstrar a importância dos vínculos criados com o território e com as práticas cotidianas compartilhadas e constitutivas. Nos alerta para a importância do território tradicional, mas também para o processo contínuo de habitar e ressignificar práticas, e de (re)territorializar os espaços ocupados.

Lourenço (2015), em etnografia realizada em Lagoinha de Cima, acerta em dizer que podemos pensar em três temporalidades significativas no decorrer da história, das memórias e das experiências relatadas pelas pessoas da comunidade: o "tempo dos escravos", "o tempo das irmandades" e o "tempo da comunidade quilombola" ou "de fazer política". Eles se encontram no "tempo de fazer política”, tempo esse que sempre permeou o tempo dos escravos e das irmandades, sempre foi necessário lutar, e hoje, eles estão continuam reivindicando seu território tradicional, afirmando sua identidade, reconstruindo e repensando seus modos de existência e resistindo aos constantes ataques ao apagamento de suas memórias e de sua forma de viver.

\section{Comunidade Quilombola de Ribeirão do Itambé}

A comunidade quilombola Ribeirão Itambé se constitui por meio de famílias extensas que se identificam como "nascidas e criadas" nas proximidades do rio Quilombo, mais especificamente, às margens de seus afluentes - rio Cachoeirinha e ribeirão Lagoinha. Localizada também no município de Chapada dos Guimarães, Mato Grosso, é situada na região da Cachoeira Rica, também conhecido como vilarejo do Peba (SILVA, 2017).

O vilarejo do Peba é parte de uma localidade mais ampla (Cachoeira Rica) formada em decorrência dos antigos garimpos de diamantes da região, que contribuíram significativamente na caracterização rural e suas espacializações. As ricas minas às margens do rio da Casca e do rio Quilombo, assim como as grandes lavouras, a pecuária e a produção dos engenhos, fundamentaram a economia local, originando a comunidade Ribeirão Itambé, união de diversos núcleos familiares que cultivam "terra de uso comum" na região.

Os núcleos familiares emprestavam os nomes dos rios, córregos e morros onde habitavam para nomear as comunidades, tais como Ribeirão Itambé, rio 
Camundá, rio Aricá, rio Acorá, rio Cachoeira Rica, rio Lagoinha, rio Lajinha e outros. Trata-se da população de escravizados e descendentes, oriundos, em sua maioria, dos engenhos Itambé, Quilombo, Buritizinho e Abrilongo, sustentadas por alianças matrimoniais e outros tipos de relações forjadas ao longo do tempo. A configuração territorial aponta para uma extensa rede de sociabilidade de uso comum e coletivo da terra entre as demais comunidades quilombolas de Chapada: Morro do Cambambi, Lagoinha de Cima e Lagoinha de Baixo, todas comunidades criadas a partir do trabalho escravo nesses grandes engenhos.

Ao que se refere aos quilombolas do Ribeirão Itambé, grande parte das famílias foram desterritorializada de sua área de ocupação histórica e tradicional, vivem esparramados por diferentes localidades, vivendo as bordas dos centros urbanos de cidades de Cuiabá, Várzea Grande e outros municípios de Mato Grosso. Atualmente, apenas 33 famílias (cerca de 120 pessoas) encontra-se no território tradicionalmente ocupado e a luta pelos direitos territoriais ainda continua.

As experiências que os quilombolas de Chapada dos Guimarães estabelecem com o território possuem base na ancestralidade e estão conectadas aos "tempos das irmandades" (SANTOS, 2010: 38). Este termo traz como referência a etnografia de Carlos Alexandre B. Plínio dos Santos (2012) sobre as comunidades negras de Mato Grosso do Sul, no episódio pós-abolição, em que essas famílias ainda não faziam uso da identidade quilombola, porém, agenciavam por meio das formas de relações de reciprocidade e mutualidade (SAHLINS, 2011). Essas redes de irmandades são práticas recorrentes nas comunidades de Ribeirão Itambé, Lagoinha de Cima e de Baixo e Morro do Cambambi.

Conforme relata Dona Vanildes, de Lagoinha de Cima, "[...] no tempo das irmandades a gente se reunia em mutirão, as famílias se reuniam para fazer a roça uma das outras. Aí produzia farinha, produzia os doces, os bolinhos, os biscoitos. Fazia a festa de São Benedito...".12

O senhor Miseu, ao relembrar sobre a época da fundação da Igreja de Santana, ressalta que ela era comandada por capelões quilombolas. Segundo ele:

- "[tinha] aqueles tiradores de reza onde entrava o pessoal dos quilombolas, que eles também tinham tiradores de reza... reza caseira, reza antiga..."13.

A fala do senhor Miseu e de Dona Vanildes fazem menção ao estabelecimento de uma conexão entre os núcleos familiares das comunidades negras de Chapada dos Guimarães.

Dona Manoelina da Silva Fernandes conta que as festas de santos são bastante recorrentes em Chapada desde os "tempos antigos" em que as famílias se reuniam para a celebração e a comunhão das festas. "[...] reuniam muita gente. Havia música, muita dança e fartura de comida. Às vezes as festas duravam semana toda e era assim que as famílias se conheciam. [Era comum] uma família convidava a outra para a festa de santo no qual eram devotos", relata ela. ${ }^{14}$

Ao recordar desses tempos dona Durvalina Dias Rodrigues (conhecida como dona Chica) relata:

Era um tempo muito bom. Era bom, porque nesse tempo as pessoas festavam, dançavam, bebiam e comiam. Não tinham brigas! A hora que vinham da festa era só trabalhar. Íamos trabalhar para fazer a próxima festa (risos). Aí tinha as festas. Tínhamos que ir aos bailes. Ai no fim de semana passava as bandeiras. Passavam e

\footnotetext{
${ }^{12}$ Notas de campo sobre a conversa realizada com Vanildes Francisca de Oliveira, em 02 de julho de 2016, em minha primeira visita a Comunidade Quilombola Lagoinha de Cima, refere-se a pesquisa de campo junto ao Projeto de Pesquisa "Cosmopolíticas, territórios, memórias e performances de comunidades negras de Chapada dos Guimarães - MT", 168/2015/PROPEQ, durante a graduação em Ciências Sociais, UFMT.

${ }_{13}$ Entrevista concedida pelo senhor Melquesedec Lechener, conhecido como Miseu, pertencente a comunidade quilombola Ribeirão Itambé, em 31 de março de 2019.

${ }_{14}$ Entrevista concedida pela Dona Manoelina da Silva Fernandes, em 01 de abril de 2017.
} 
pousavam nas casas. Pousavam na casa da minha avó [Lourença], pousavam nos vizinhos. Aí nós dançávamos. Quando pousavam na casa dos vizinhos, nos dançávamos. E aí nós íamos à casa dos outros, levar a bandeira e nos dançávamos também. E assim ia a semana toda. (...). Quando eram as bandeiras, tocavam sanfona. Quando não era sanfona, tocavam violão. (...). Eu gostava de dançar, não tinha outra diversão, era só essa diversão. Ai quando vinha, quando terminava ali, voltava para a roça. Era a semana inteira na roça, trabalhando, fazendo farinha, fazendo arroz, cortando arroz. Era arrancando feijão, quebrando milho. ${ }^{15}$

Senhor Gervásio acrescenta dizendo: “...[essas] festas de Santo são passadas de geração em geração", assim como também as "rezas de São Gonçalo, as festas de São Benedito", e sempre são regadas "pelas rodas de viola de cocho e ganzá, lá se tocava o verdadeiro cururu e siriri". ${ }^{16}$ Conforme a antropóloga Patrícia Silva Osório (2012: 237), cururu e siriri são duas manifestações rotuladas como folclóricas e bastante difundidas no Mato Grosso. O cururu é uma dança de caráter religioso, que se utiliza de instrumentos músicas como a viola de cocho ${ }^{17}$ e o ganzá18, sendo esse tocado por homens que improvisam toadas em tons de desafios. Já o siriri trata-se de uma dança feita em pares, em roda e fileiras, ao som do reco-reco, viola de cocho e tambor ${ }^{19}$.

Ainda hoje as comunidades (e famílias) quilombolas realizam as Festas de Santo, que possuem um calendário próprio e, cujo as celebrações, são distribuídas no decorrer dos meses do ano. As pesquisas etnográficas junto às comunidades permitiram catalogar aproximadamente 22 festas realizadas por famílias quilombolas, geralmente nas casas dos festeiros que vivem no território tradicional, agregando as comunidades do Peba (Ribeirão Itambé), Biquinha, Varginha, Casca, Água Fria, Morro do Cambambi, Pingador, Lagoinha de Cima, Cachoeira Bom Jardim, João Carro e Bocaina do Aguaçu.

Há também as festas realizadas pelas comunidades do bairro Aldeia Velha, Cohab Véu de Noiva e a festa da Matriz de Chapada, que se localizam na região urbana. Todas elas mobilizam milhares de pessoas, entre familiares, amigos, devotos e convidados "de fora", que, para além de homenagearem os santos, agenciam uma rede de sociabilidade a fim de reencontrar os parentes, pagar promessas, dívidas e até aqueles que vão apenas para apreciar as festas, perpetuando práticas culturais dos tempos remotos da pós-abolição até a contemporaneidade.

Devido à essas Festas de Santo, ou mesmo de visitas periódicas, como acontece em Lagoinha de Cima, diversas famílias se deslocam das mais variadas localidades para o território de ocupação tradicional, estabelecendo um fluxo contínuo de deslocamentos que configuram uma rede de relações e agenciamento, reforçando os laços de sociabilidades, parentesco e memória. Podemos dizer que, o que caracteriza a contemporaneidade dessas festas, é que ela retém as reminiscências das tradições e a ressignificação do processo de reterritorizalização dessas famílias, contidas nesse fluxo e conectam pessoas ao território.

Dona Claudia Celina, ao se referir às festas do Divino da Chapada e de São Benedito, no Vilarejo do Peba, faz referência à catira ${ }^{20}$ e ao cururu, preservados nas festas até hoje, como elementos simbólicos presentes nas vivências dos seus antepassados nos antigos quilombos.

\footnotetext{
${ }^{15}$ Entrevista concedida pela Dona Durvalina Dias Rodrigues (Dona Chica), em 22 de julho de 2017.

${ }_{16}$ Entrevista concedida pelo senhor Gervásio Moreira da Silva, em 05 de setembro de 2015.Idem.

17 Viola feita de tronco de madeira e cordas de tripas de mamíferos (ou cordas sintéticas). Reconhecido em 2004 como patrimônio nacional, registrado pelo Instituto do Patrimônio Histórico e Artístico Nacional (IPHAN).

${ }_{18}$ Juntamente com o reco-reco, trata-se de um instrumento de percussão feito com a taquara medindo cerca de 40 a $70 \mathrm{~cm}$. Geralmente tocada com uma vareta ou garfo.

19 Instrumento de percussão também chamado de mocho ou tamboril. Uma espécie de banco de madeira com assento de couro. Geralmente tocado com duas baquetas de madeira.

${ }_{20}$ É uma dança coletiva e popular marcada pelas batidas dos pés e mãos dos dançarinos.
} 
[Festa do] Divino da Chapada, São Benedito, tudo passava aqui no Peba (...). Daí fazia jantar, aí dançava a noite toda. Às vezes eram dois dias, três dias de festa. [Tinha] Cururu, [tinha] Siriri. Então, eles gostavam muito da catira. A catira veio dos quilombolas, sabia? Nossos bisavôs, que a gente conversava com eles..., aí eles falavam que a catira e o cururu já vieram de lá dos quilombolas [referindo-se aos negros do período escravocrata] e veio passando até nós, até hoje tem a viola de cocho [... $]^{21}$

Se no território tradicional as festas de santo são mecanismos de estabelecimento dessa rede de relações, na cidade as famílias se agenciam através das "reuniões de famílias", onde, por vezes, eles se reúnem para contar histórias. As reuniões da família Alves da Guia agregam cerca de 60 a 100 pessoas. Esses sujeitos remontam às reminiscências de seus antepassados e remetem ao período em que ainda desfrutavam do uso comum da terra. O que se ouve nos almoços de domingo são as histórias de fatos acontecidos no território tradicional, narrativas sobre a infância e da juventude nos quilombos. É como se o cenário das casas trouxesse a ressignificação dos antigos quilombos. Por meio dos quintais abertos e compartilhados com os demais membros da família - filhos, sobrinhos e netos, eles conectam-se.

Assim como as reuniões aconteciam tanto no território tradicional como nas casas da cidade, o cultivo de plantas, mesmo que cerceados em pequenos potes, latas e objetos improvisados, também foi uma prática continuada. Dona Manoelina cultiva suas "mudinhas" e "plantinhas" na esperança de "quando sair as terras eu levar tudo para lá”. São plantadas cebolinha, salsa, pimenta coentro, couve, hortelã, ervas de alecrim, erva-cidreira, samambaias e folhagens, árvores frutíferas como caqui, jabuticaba, maçã, caju, mamão, manga, goiaba, até plantas medicinais, como quitaia, dipirona, boldo, quebra-pedra, camomila, babosa, entre outras.

De maneira geral as casas possuem poucos cômodos - dois quartos, sala, cozinha, banheiro. É interessante que mesmo tendo cozinha interna com fogão a gás, as mulheres preferem cozinhar no quintal, à beira do fogão a lenha, assim como é feito em todas as comunidades de Chapada dos Guimarães. Regada à banha de porco e toucinho, o cheiro do feijão, juntamente com o "cozidão" (de carne com mandioca) ou peixada, arroz, farofa de banana, pirão, vai produzindo um cheiro que os leva de volta aos "tempos antigos", à época em que "a gente morava tudo lá nas terras dos nossos pais" e ao território tradicional.

É como se o cheiro dos alimentos remetesse a um lugar, há um tempo passado, fatos acontecidos que, ao serem contados, conectam o passado ao presente. Conforme o historiador David Lowenthal (1998, p.83) "relembrar o passado é crucial para nosso sentido de identidade: saber o que fomos, confirma o que somos. Nossa continuidade depende inteiramente da memória; recordar experiências passadas nos liga a nossos eus anteriores, por mais diferente que tenhamos nós tornados". Assim, esses cheiros e sabores acionam os "lugares de memórias" (NORA, 1993) no qual os sujeitos recriam os "quilombos" por meio de seus "corpos”. São essas memórias narradas que os conectam "pessoas" à "lugares”. Recriam a maneira pela qual esses quilombolas procuram reconstruir seus modos de existência. Logo, os vínculos sociais partilhados pela territorialidade fazem com que os quilombolas do Ribeirão Itambé, vivam na iminência e esperança do retorno às terras tradicionais. 


\section{Comunidade Quilombola do Morro do Cambambi}

Localizada a 30 quilômetros do município de Chapada dos Guimarães - MT, a comunidade do Morro do Cambambi possui cerca de vinte e uma localidades identificadas em campo. Foi reconhecida pela Fundação Cultural Palmares na data de cinco de maio de 2009.

A palavra Cambambi, originária da palavra africana Kambambi, "faz referência à região que constituía o centro pulsante do reino do Dongo, na Angola quinhentista, uma região reconhecida pela sua fartura em minérios, como a prata, e, por isso, tornou-se o "primeiro alvo militar dos portugueses em solo africano" (LOPES, 2017: 39). A referência dá nome ao morro imponente, místico, conhecido localmente por suas histórias e que, olhado de todos os lados, por todos os ângulos, possui três pontas iguais de onde quer que o observador esteja.

O Morro do Cambambi se configura como a principal fonte de abastecimento hidrológico de toda a região, devido às suas 13 nascentes, origem de riachos, mananciais, rios e cachoeiras. Em conversas com as famílias moradoras na região, há um grande entendimento de que o Morro do Cambambi é "a caixa d'água para toda a região", fonte de vida para todos.

Com as últimas ações de fazendeiros nos desmatamentos realizados em cima do morro, a preocupação é coletiva quanto a possibilidade de esgotamento de água, fato que já vem acontecendo com a secagem de alguns poços artesianos, rios e riachos nos últimos anos. Situação essa que também ocorre em outras comunidades tradicionais pelo Brasil, como na Comunidade Chiquitana do Portal do Encantado e que gera aflição em todos, frente a falta de água e ao poder dos proprietários atuais sob esses territórios das áreas devastadas (PACINI, 2012).

No decorrer da pesquisa de campo foram identificadas vinte e nove localidades distribuídas pelo território do Cambambi. Em cada localidade se encontram uma ou mais famílias que se identificam a partir da presença e permanência de seus ancestrais ao longo do tempo. Independentemente do quantitativo de famílias que habitam as localidades, elas entendem e nomeiam tal local como sendo uma comunidade distinta, concedendo a ela um nome para diferenciá-la das demais. Geralmente, o nome é dado a partir de características do ambiente, dos recursos naturais disponíveis ali ou em algo ligado a alguma antiga "propriedade" com sentidos culturais específicos que ali existiu.

Dentre as localidades, algumas são ativas e habitadas até os dias de hoje, outras, por sua vez, já se encontram desativadas devido à morte de seus moradores mais antigos, expropriação após a construção da Usina Hidrelétrica do Manso ${ }^{22}$, invasão/compra das terras por fazendeiros, ou à impossibilidade de sustento no local. Todavia, são sempre lembradas como localidades porque moram ali as memórias de seus antepassados.

Não se trata de várias comunidades isoladas espalhadas à beira do rio Quilombo, e sim localidades relacionais e conectadas por diversas relações de parentesco, de religiosidade e, agora, associativas, que os mantêm próximos, apesar das distâncias e dificuldade de encontros. As festas de santo, encontros de famílias, orações, reuniões das associações, acabam sendo espaços de encontros e de manutenção do parentesco, compadrios, inimizades e alianças, que conferem a eles

22 A Usina Hidrelétrica do Manso é um empreendimento do Governo do estado de Mato Grosso, em parceria com a iniciativa privada no rio Manso e Cuiabá. A barragem foi inaugurada em 2000, momento em que impactou diretamente a vida de todos que viviam às margens dos rios e afluentes, no que tange ao abastecimento de água e moradia, forçando algumas famílias a se deslocarem de suas propriedades. Disponível em: < https://www.furnas.com.br/subsecao/124/usina-de$\underline{\text { manso---212-mw?culture }=\text { pt }}>$ Acesso em 30 de nov de 2020. 
momentos de sociabilidades, fortalecendo assim a relação de comunidade desse território.

Assim, a localidade, que é mais que o espaço físico-geográfico, pois diz respeito a algo mais permanente baseado no parentesco e nos vínculos ancestrais, e a comunidade - entendida como um espaço vívido, composto pelas relações de inimizade e pelos conflitos, que são mais fluídos - configuram uma rede de relações que é tecida dando sentido não só a noção de território, mas de construção das próprias pessoas. Trata-se de um território eternizado no diálogo, nas relações de parentesco, alianças, inimizades, habitado pelas memórias e pelos antepassados.

As famílias entre si, vindas das mais diversas localidades, possuem, entre elas, vínculos de parentesco estabelecidos pelos casamentos entre primos, fator que os aproxima ainda mais, independentemente das distâncias que os separa. É o que me contou Dona Marcela ao comentar sobre a sua família espalhada pela região:

\begin{abstract}
A família é toda ligada. Minhas duas irmãs (a Francisca e a Enedina) casaram-se com os filhos de Dona Felícia, que era irmã de vovó Antônia (apelido de Taía). Então, minhas irmãs casaram-se com os sobrinhos de vovó, que é irmã da tia Felícia. A Felícia, além do Seu José, teve o Donato e o Adalberto, de homens. De mulher, teve a tia Ditinha e o Inácio, que é meu cunhado também. A Claudina se casou com o sobrinho da tia Felícia também, o Osvaldino, que é sobrinho da Dona Luzia, que é mulher do Seu Genésio, mãe do Zico. A mãe do Zico e o pai do Osvaldino são irmãos. Osvaldino e o Zico são primos primeiros e minhas duas irmãs casaram-se com os tios do Zico e do Osvaldino (o Basílio e o Inácio). O Adalberto é casado com a minha prima, que é neta da avó Antônia, que eu esqueci de colocar que ela teve a Dona Paulina também, além da Dona Cezarina. ${ }^{23}$
\end{abstract}

“A nossa família está no mesmo lugar, vai ali e volta”, diz Dona Marcela fazendo menção à tantos casamentos entre primos e parentes, não somente em sua família, mas na região.

\begin{abstract}
Mas aqui não é só eu. A maioria aqui é assim. E dessa família do Zico ainda está até hoje, porque eu e o Zico, nós não vamos ter mais filho. Minha filha também se casou com um primo, mas mais distante. O filho do Zico já se casou com uma mulher que também não tem mais a ver conosco, porque saíram daqui. Os que ficaram lá no Morro, que é a família do Zico, do lado da mãe e do pai, que são irmãos também. A tia Luzia é casada com o tio Fião e a irmã da tia Luzia se casou com o irmão do tio Fião (casamentos trocados), entendeu? Um casou-se com uma irmã e o outro se casou com a irmã do outro e agora os primos estão lá e estão fazendo a mesma coisa. Estão se casando e já tem o caso lá de 3 filhos, que veio com sequela porque o sangue está voltando. ${ }^{24}$
\end{abstract}

Contudo, nem sempre os laços de sangue determinam o parentesco. As relações são construídas pela "consideração", termo nativo usado para expressar os vínculos não-consanguíneos.

Ela é de consideração. Foi adotada pela tia Julia, então não conheço bem a origem da família dela, mas conheço da mãe adotiva dela. Ela não é de sangue. Hoje eu sei que ela é casada com um primo meu que é filho da tia Paulina. Hoje ela faz parte da família porque ela se casou com um primo nosso né?! E meu irmão é casado com a filha dela, o José. ${ }^{25}$

As relações são tão diversas que se torna até difícil explicar todos os laços que unem as pessoas, "[é] assim, é uma rede e um punho e você puxando os barbantinhos e colocando tudo aí”. Ao questionar Dona Marcela sobre o que ela pensa a

${ }_{23}^{23}$ Entrevista concedida pela Dona Marcela Pedroso, em 15 de setembro de 2019. 
respeito desses casamentos trocados, ela afirma que sempre existiu e não sabia dizer se era "cultura", falta de informação ou de opção:

\begin{abstract}
Quando a gente entra na idade de acasalamento, no meio do mato, não se tem um parceiro e começa a achar o primo bonito e os encontros sempre aconteciam nas festas de santo. Ali ficava, namorava e muitos não se casavam, eram roubados. Sempre a gente ouvia: "Fulano roubou a filha de Cicrano." [...] naquela época, eu acho que era isso, porque aquele povo antigo ainda tinha medo do pecado e hoje não. Eu acho que o mundo não tem mais medo do pecado. O que vale é a lei deles, até esquece de pensar em Deus, mas, lá em casa, mamãe falava: "Primo com primo, irmão com irmão não pode." Todo mundo não podia deitar junto, não podia ver a irmã tomando banho. Quando ficava mocinha, tinha que vestir a combinação para não ficar marcando o corpo. Tinha medo do pecado. Hoje não. ${ }^{26}$
\end{abstract}

Assim, as famílias das diferentes localidades acabam por representar um esboço de um mapa local que se encontra nas reminiscências dessas pessoas, configurando uma rede de conexão de conhecimentos e lembranças que se emaranha e que os mantém unidos, interrelacionados, apesar das distinções nominais do território em localidades. Tal mapa é mencionado por cada um deles de acordo com suas relações constituídas entre parentes e não parentes de cada localidade, juntamente com a memória coletiva compartilhada por eles, demonstrando um senso de comunidade diverso, mas sempre imbrincado.

Os moradores que ainda permanecem no território tradicional não deixam de mencionar lugares, pessoas ou famílias que já faleceram, mas que continuam presentes nas histórias dos locais e da comunidade. A compreensão das pessoas de forma a relacionar os ancestrais aos territórios ocupados ou desocupados atualmente, assim como as relações estabelecidas entre as pessoas de Lagoinha de Cima e Ribeirão Itambé com seus territórios, demonstram, mais uma vez, a importância desses locais tradicionalmente ocupados e vivenciados nas práticas cotidianas enquanto parte integrante da constituição de suas identidades.

Assim, quando, no campo, observa-se a forma como eles remetem às localidades como sendo comunidades, é possível perceber que se referem a núcleos familiares, mesmo incorporando os que já faleceram. Não se trata de um conglomerado de quilombos, dispersos e separados, pois todos estão interligados, estabelecendo diversas relações entre si. Identificar cada localidade como comunidade, mesmo que ali viva somente uma família atualmente, é uma forma pensada por eles para nomear e situar os seus núcleos familiares que possuem relações com os locais nos quais viveram e ainda vivem os parentes, compadres ou conhecidos.

Qualquer localidade próxima de uma queda d'água (cachoeira), por exemplo, onde se encontra apenas uma família, é possuidora de uma nomeação específica, geralmente o nome da cachoeira, como é o caso de Pingador, Biquinha, Água Branca, Cachoeira do Bom Jardim, Água Fria, recebendo o status do que entendem como comunidade, pelo fato de ali se encontrar uma família completa. Tratase de mapas físicos e cosmológicos, de uma cartografia nativa, para expressar a forma como eles territorializam-se. Nesse sentido, fazer política em Cambambi também é nomear e codificar, de acordo com a sua realidade, com a vivência enquanto família e comunidade. A partir da denominação da localidade, tal denominação torna-se usual por todos para a identificação espacial do território.

Ao serem nomeadas essas comunidades refletem as memórias e significados para as pessoas quilombolas de Cambambi como para os quilombolas do Ribeirão Itambé, que reconhecem como seu território as mesmas regiões que são reivindi- 
cadas pela Associação do Morro do Cambambi. O território das duas comunidades é contíguo, extrapolando, muitas vezes, questões legais e geopolíticas legalizadas. Ambas possuem o rio Acorá como marco divisório entre as duas comunidades, segundo os senhores Antero e o Luiz, presidentes das associações de Cambambi e Itambé, respectivamente, existindo somente divergências referentes aos limites dos territórios.

Os dois quilombos foram criados a partir das dissidências do Engenho de Mamão, ponto, inclusive, dessas questões da divisão de terras, pois ela é uma área de importância histórica para ambas as comunidades por ser a origem de suas famílias. Além dos territórios limítrofes e compartilhados de Cambambi e Itambé, a mesma situação também ocorre com as comunidades de Lagoinha de Cima e Lagoinha de Baixo que apresentam seu elo histórico e familiar com bases em ancestrais comuns que trabalharam no Engenho do Abrilongo.

É neste sentido que as localidades e territórios compartilham, ampliam, permeiam e pertencem a essas pessoas que vivem em uma comunidade (ou outra) mas que tem uma história em comum, de um território vasto, cheio de significados e lembranças de quem passou e de quem se é hoje a partir deles.

\section{Considerações finais}

O processo histórico das ocupações na região de Serra Acima, hoje Chapada dos Guimarães, mostra como esse território foi ocupado pelos povos da etnia Bóe (Bororo), Kurâ-Bakairi, entre outras etnias, antes da chegada de portugueses, espanhóis e, especialmente, de pessoas de diferentes nações africanas para trabalharem como escravas nos garimpos, engenhos e fazendas. O que resultou na grande quantidade de comunidades quilombolas que apresentam, a partir das etnografias realizadas, uma rede de sociabilidade que agrega laços de parentesco, consideração, práticas, trocas e circulação de alimentos, festas, histórias e localidades que interligam as pessoas quilombolas das comunidades de Lagoinha de Cima, Ribeirão Itambé e Morro do Cambambi.

As narrativas mostram, nos diferentes contextos, formas de (re)significação de seus territórios, geometrizando formas de habitar que constituem, com o passar do tempo, um agenciamento político de sua forma de viver e de se relacionar, que amplia a ideia pré-concebida sobre os quilombos, na medida em que se estendem, também, por sobre os espaços urbanos. O território significa, dá sentido às relações, e os novos espaços habitados, nas cidades, por exemplo, evidenciam as agencias nesses espaços (re)signifados que carregam em si as vivências e memórias de suas terras tradicionalmente ocupada.

As formas de habitar das populações dessas comunidades demonstram a importância das relações com o território enquanto constitutivas de relações familiares amplas e diversas, ao mesmo tempo que dão sentido e permeiam seus processos identitários na constituição dessas pessoas quilombolas. Morar, manter práticas ancestrais, plantar, celebrar as festas de santo, fazer visitas e "reuniões de família", trocar alimentos, constituem em si ações de resistência e luta na continuidade de suas histórias e reafirmam a importância do território tradicional no prosseguimento dessas reminiscências e dessa forma de ser e (re)existir.

Considera-se, assim, que as redes de sociabilidades criadas entre as famílias e comunidades são constitutivas da sociabilidade dos quilombolas de Chapada, cujo processos sociais resultam de um conjunto complexo de elementos. Dessa forma, essas famílias operam como eixo de relações que, por meio delas, circulam histórias em comum, provenientes do contexto da escravidão, da exploração, da 
violência e, ao mesmo tempo, revela que cada uma delas encontrou múltiplas formas de se organizar para sobreviver e ressignificar o cotidiano em diversos espaços. Não se trata apenas histórias de violência, mas também histórias de resistências, trocas, alianças, casamentos, festas, conflitos e modos de vida. Esses relatos reforçam os laços afetivos entre essas comunidades, interligando famílias a círculos sociais, demonstrando a ocupação histórica cujo o território contiguo e extenso é ressemantizado ao longo do processo de reivindicações de direitos como sujeitos quilombolas.

Recebido em 3 de outubro de 2020. Aceito em 12 de dezembro de 2020.

\section{Referências}

ARRUTI, José Maurício. Mocambo: Antropologia e História do processo de formação quilombola. Bauru: Edusc, 2006.

ARRUTI, José Maurício. "Ente campo e cidade: quilombos, hibridismos conceituais e vetores de urbanização". In: OLIVEIRA, Osvaldo Martins de (org.). Direitos Quilombolas e dever do Estado em 25 anos de Constituição Federal de 1988. Rio de Janeiro: Associação Brasileira de Antropologia, 2016. pp. 241-256.

BANDEIRA, Maria de Lourdes. "Terras Negras: invisibilidade expropriadora". In: Terra e Textos e Debates: Terras e Territórios de Negros no Brasil. UFSC, 1991. pp 7-24.

BRASIL. Furnas - Empresa Eletrobras. Usina de Manso - 220MW. Disponível em <https://www.furnas.com.br/subsecao/124/usina-de-manso---212-mw?culture $=$ pt $>$ Acesso em 30 de nov de 2020.

CARDOSO DE OLIVEIRA, Luís Roberto. "Honra, Dignidade e Reciprocidade". In: MARTINS, P. H.; NUNES, B. F (orgs.). A nova ordem social: perspectivas da solidariedade contemporânea. Rio de Janeiro: Vozes, 2004.

CASTRO, Marina M. R. Pessoa, gênero e cuidado na comunidade quilombola Lagoinha de Cima, Chapada dos Guimarães - Mato Grosso. Dissertação de Mestrado, Antropologia Social, UFMT, 2018.

CRIVELENTE, Maria Amélia A. Alves. Poder e cotidiano na Capitania de Mato Grosso: Uma visita aos senhores de engenho do Lugar de Guimarães. 1751-1818. Revista de Demografia Histórica, XXI (II): 129-152, 2003.

FLORENCE, H. Viagem fluvial do Tietê ao Amazonas: de 1825 a 1829. São Paulo: Cultrix/Edusp, 1977. 
FRANCO JUNIOR, José Batista. Etnografia dos modos de fazer política no Quilombo do Morro do Cambambi: Chapada dos Guimarães - MT. Dissertação de Mestrado, Antropologia Social, UFMT, 2020.

LOWENTHAL, David. Como conhecemos o passado. Projeto História, 17: 63201, 1998.

LOURENÇO, Sonia Regina. A emergência de identidades étnicas das comunidades quilombolas de Chapada dos Guimarães. Afro-Ásia, 49: 52 9-40, 2015.

LOURENÇO, Sonia Regina. "Comunidades Quilombolas de Chapada dos Guimarães”. In: OLIVEIRA, O. M de O. (org.). Direitos Quilombolas e dever do Estado em 25 anos de Constituição Federal de 1988. Rio de Janeiro: Associação Brasileira de Antropologia, 2016.

MADUREIRA, Elisabeth. "Resgate do processo de ocupação de terras no Brasil e em Mato Grosso". In: MACHADO, Laís Aparecida Machado; FRAGA, Leila Miguel. História e Antropologia no Vale do Rio Manso (MT). Goiânia: Ed. da UCG, 2006.

MAUSS, Marcel. "Ensaio sobre a dádiva" [1935]. In: Sociologia e Antropologia. São Paulo: Cosac \& Naify, 2003.

MELLO, Marcelo Moura. Reminiscências dos quilombos. Territórios da memória em uma comunidade negra rural. São Paulo: Ed. Terceiro Nome, 2012.

NORA. Pierre. Entre memória e história: A problemática dos lugares. Projetos História, 10 (10): 7-28, 1993.

O'DWYER, Eliane C. (Org.). Quilombos: identidade étnica e territorialidade. Rio de Janeiro. Editora FGV, 2002. pp. 83-108.

OSORIO, Patrícia Silva. Os Festivais de Cururu e Siriri: mudanças de cenários e contextos na cultura popular. Anuário Antropológico, 37 (1): 237-260, 2012.

OVERING, Joanna. Elogio ao cotidiano: a confiança e a arte da vida social em uma comunidade amazônica. Mana, 5 (1): 81-107, 1999.

PACINI, Aloir. Identidade étnica e território Chiquitano na fronteira (BrasilBolívia). Porto Alegre: IFCH/UFRGS, 2012.

PINA-CABRAL, João de; SILVA, Vanda Aparecida da. Gente Livre: consideração e pessoa no baixo sul da Bahia. São Paulo: Terceiro Nome, 2013.

SAHLINS, Marshall. What Kinship is - and is not. Chicago: The University of Chicago Press, 2011.

SEEGER, Anthony; DA MATTA, Roberto; VIVEIROS DE CASTRO, Eduardo B. A construção da pessoa nas sociedades indígenas brasileiras. Boletim do Museu Nacional, Série Antropologia, 32 (1): 2-19, 1979.

SILVA, Cassiana Oliveira. Etnografia do território quilombola Ribeirão do Itambé: território e etnicidade em Chapada dos Guimarães. Monografia de Graduação, Ciências Sociais, UFMT, 2017. 
SILVA, Danielli K. Pascoal. Cosmologia quilombola: entre arrumações, benzeções e seres não-humanos. Monografia de Graduação, Ciências Sociais. UFMT, 2014 .

SYMANSKI, Luís Cláudio P. Cerâmicas, identidades escravas e crioulização nos engenhos de Chapada dos Guimarães - MT. História Unisinos, 4 (3): 294-310 2010.
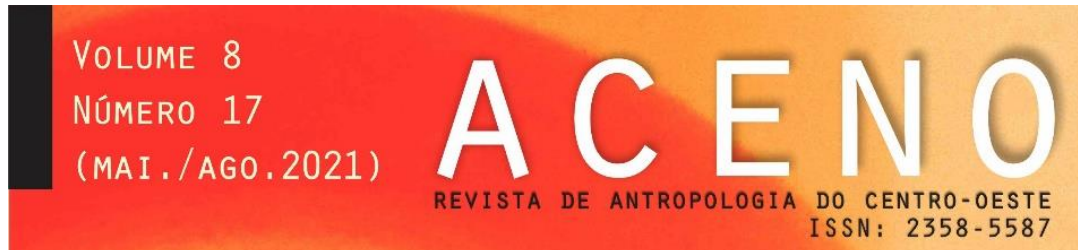

CHAMADA DE ARTIGOS

DOSSIE TEMÁTICO:

RETOMADAS E RE-EXISTÊNCIAS

INDÍGENAS, NEGRAS E QUILOMBOLAS

COORDENADORXS:

SONIA REGINA LOURENÇO (PPGAS/UFMT)

CAUÊ FRAGA MACHADO (NUPACS/UFRGS)

SANDRO JOSE DA SILVA (PGCS/UFES)

$\mathrm{E}$ ste dossiê temático da ACENO tem como objeto as territorialidades e os processos de identificação negras, quilombolas e indígenas. A proposta busca chamar a atenção para processos de identificação $e$ territorialização que forneçam perspectivas adicionais às análises consolidadas que se dedicaram às tradições, à etnogênese e às situações de fronteiras étnicas, mais afeitos às mediações com o Estado-nação, que privilegiaram as relações políticas, agentes e agência da burocracia. Um movimento renovado de coletivos indígenas, quilombolas e negros tem revisitado tais abordagens mediante a crítica sistemática aos padrões eurocentrados, brancos e coloniais que produziram a invisibilização sistemática do que esses movimentos consideram relevantes. Dentre essas, categorias como "retomada" e "resistência" - não apenas como reação, mas como re-existir - territorial e existencial são fundamentais quando tomadas como conceitos que descrevem diferentes vínculos entre actantes dos mais diversos modos de existência.

A proposta privilegiará a publicação de etnografias e reflexões teóricas acerca desse novo cenário no qual entes produzem reflexões cosmopolíticas e modos de agir com (ou contra) o Estado-nação de modos antes insuspeitos. Espera-se que as contribuições contemplem a diversidade regional, étnicoracial e de gênero, bem como contribuições dos povos originários e povos e comunidades tradicionais.

PRAZO FINAL DE SUBMISSÃO: 30 DE ABRIL DE 2021
Trata-se de consolidar olhares não pela via da memória ou da prova, mas pela cosmologia e relacionalidade estendida a todos existentes, recuperando algo dado como perdido ou inexistente. Pretende-se de sublinhar identificações e territorialidades que encontram novas maneiras de se expressar, retomando terras, práticas, contato com seres, objetos, linguagens sem que essas nunca tenham sido perdidas de fato. 